\title{
Synthesis of a Glycine Transporter 1 Inhibitor
}
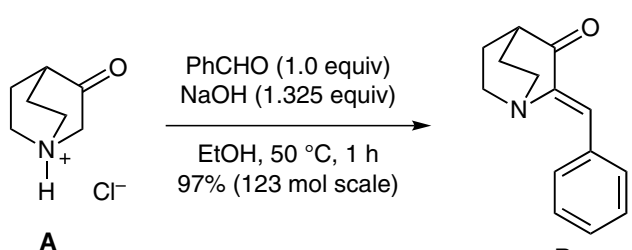

mp not reported
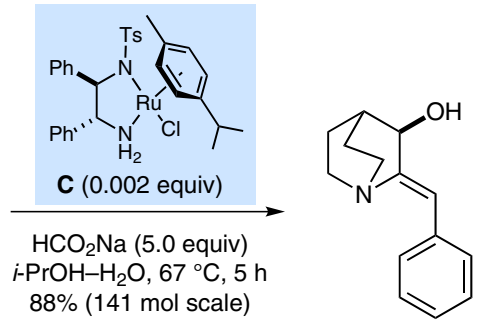

D

mp not reported

er $>97: 3$

$t$-AmONa ( 0.1 equiv) $\mathrm{Cl}_{3} \mathrm{C}-\mathrm{CN}$ ( 1.0 equiv) xylenes, $23^{\circ} \mathrm{C}, 1 \mathrm{~h}$ $125 \mathrm{~mol}$ scale

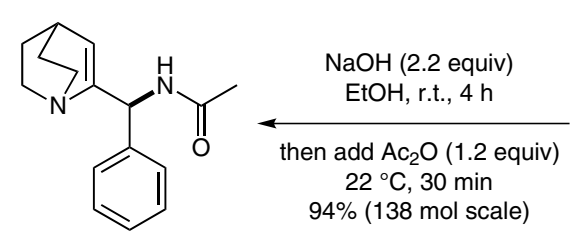

$\mathrm{mp}$ not reported

$$
\mid \begin{aligned}
& \mathrm{H}_{2}(3.6 \text { bar }), 5 \% \mathrm{Pd} / \mathrm{C} \\
& \mathrm{D} \text {-tartaric acid (1.0 equiv) } \\
& \mathrm{MeOH}, 33^{\circ} \mathrm{C}, 4 \mathrm{~h} \\
& 94 \%(58.5 \mathrm{~mol} \text { scale })
\end{aligned}
$$

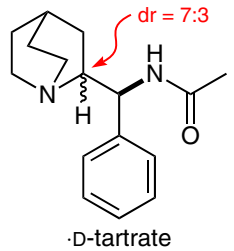

H

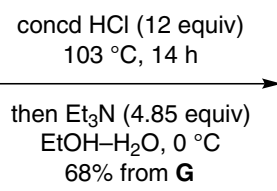

$68 \%$ from $\mathrm{G}$

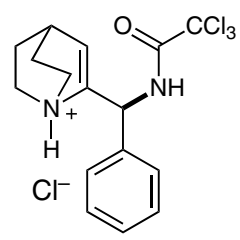
mp not reported

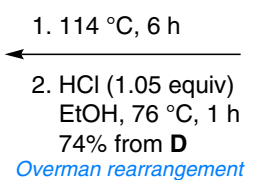

Overman rearrangement

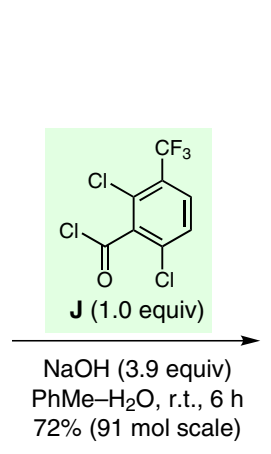

-tartrate

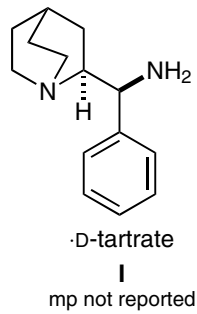<smiles>O=C(NC(c1ccccc1)[C@H]1CC2CCN1CC2)c1c(Cl)ccc(C(F)(F)F)c1Cl</smiles>

Glycine Transporter 1 Inhibitor mp not reported

E
Synthesis of Natural

Products and

Potential Drugs

\section{Key words}

glycine transporter 1 inhibitors

Noyori asymmetric transfer

hydrogenation

Overman

rearrangement

[3,3]-sigmatropic rearrangement

trichloroacetimidate

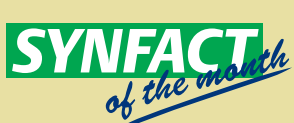

Significance: The target glycine transporter 1 (GlyT1) inhibitor was of interest for the treatment of schizophrenia and acute manic disorders. Key steps in the synthesis were (1) a Noyori asymmetric transfer hydrogenation ( $\mathbf{B} \rightarrow \mathbf{D})$, and (2) an Overman rearrangement by which allylic alcohol D was converted into the allylic amide $\mathbf{F}$. This is the first example of a multikilogram scale-up of an Overman rearrangement.

SYNFACTS Contributors: Philip Kocienski

Synfacts 2012, 8(6), 0583 Published online: 16.05.2012

Dol: 10.1055/s-0031-1290994; Reg-No.: K02812SF
Comment: The eight-step synthesis depicted proceeded in 20\% overall yield and delivered 24.2 $\mathrm{kg}$ of API. The initial isolated material was an undesired polymorph, but simply suspending the solid in water and heating to $55^{\circ} \mathrm{C}$ for two hours resulted in smooth conversion into the desired polymorph. 